\title{
TU/e EN⿴HONE

\section{Regional electrical activation and mechanical function in the partially ischemic left ventricle of dogs}

\section{Citation for published version (APA):}

Delhaas, T., Arts, M. G. J., Prinzen, F. W., \& Reneman, R. S. (1996). Regional electrical activation and mechanical function in the partially ischemic left ventricle of dogs. American Journal of Physiology : Heart and Circulatory Physiology, 271, $\mathrm{H} 2411-\mathrm{H} 2420$.

\section{Document status and date:}

Published: 01/01/1996

\section{Document Version:}

Publisher's PDF, also known as Version of Record (includes final page, issue and volume numbers)

\section{Please check the document version of this publication:}

- A submitted manuscript is the version of the article upon submission and before peer-review. There can be important differences between the submitted version and the official published version of record. People interested in the research are advised to contact the author for the final version of the publication, or visit the $\mathrm{DOI}$ to the publisher's website.

- The final author version and the galley proof are versions of the publication after peer review.

- The final published version features the final layout of the paper including the volume, issue and page numbers.

Link to publication

\section{General rights}

Copyright and moral rights for the publications made accessible in the public portal are retained by the authors and/or other copyright owners and it is a condition of accessing publications that users recognise and abide by the legal requirements associated with these rights.

- Users may download and print one copy of any publication from the public portal for the purpose of private study or research.

- You may not further distribute the material or use it for any profit-making activity or commercial gain

- You may freely distribute the URL identifying the publication in the public portal.

If the publication is distributed under the terms of Article 25fa of the Dutch Copyright Act, indicated by the "Taverne" license above, please follow below link for the End User Agreement:

www.tue.nl/taverne

Take down policy

If you believe that this document breaches copyright please contact us at:

openaccess@tue.nl

providing details and we will investigate your claim. 


\title{
Regional electrical activation and mechanical function in the partially ischemic left ventricle of dogs
}

\author{
TAMMO DELHAAS, THEO ARTS, FRITS W. PRINZEN, AND ROBERT S. RENEMAN \\ Departments of Physiology and Biophysics, Cardiovascular Research Institute Maastricht, \\ University of Maastricht, $6200 \mathrm{MD}$ Maastricht, The Netherlands
}

\begin{abstract}
Delhaas, Tammo, Theo Arts, Frits W. Prinzen, and Robert S. Reneman. Regional electrical activation and mechanical function in the partially ischemic left ventricle of dogs. Am. J. Physiol. 271 (Heart Circ. Physiol. 40): H2411H2420, 1996.-During normoxia, asynchronous electrical activation of the left ventricle significantly affects regional mechanical performance. Regional fiber strain and external work during the ejection phase are found to be lower in early-activated than in late-activated regions. Because electrical activation is known to be delayed during ischemia, the present study was designed to investigate the influence of this electrical asynchrony on regional fiber strain, if any, during moderate and severe myocardial ischemia. Regional electrical activation time $\left(t_{\mathrm{ea}}\right)$ and fiber strain during the ejection phase $\left(e_{\mathrm{f}, \mathrm{e}}\right)$ were measured in the epicardial layers of the left ventricular anterior wall during normoxia and after $15 \mathrm{~min}$ of total occlusion $(n=5)$ or $30,60,120$, and $180 \mathrm{~min}$ of partial occlusion of the left anterior interventricular coronary artery (LAICA; $n=11$ ). Myocardial blood flow (MBF) was assessed with radioactive microspheres. Blood gases, $\mathrm{pH}$, and lactate and $\mathrm{P}_{\mathrm{i}}$ contents were determined in arterial, local venous, and coronary sinus blood. During normoxia, $t_{\mathrm{ea}}$ and $e_{\mathrm{f}, \mathrm{e}}$ were similar in various epicardial regions of the left ventricular anterior wall. During total LAICA occlusion, in the ischemic area, subepicardial MBF decreased from $0.86 \pm$ $0.36(\mathrm{SD})$ to $0.18 \pm 0.09 \mathrm{ml} \cdot \mathrm{g}^{-1} \cdot \mathrm{min}^{-1}$ and subepicardial $e_{\mathrm{f}, \mathrm{c}}$ decreased from $-0.11 \pm 0.02$ to $-0.01 \pm 0.01$, whereas the delay in $t_{\mathrm{ea}}$ between the normoxic basal-Iateral and ischemic apical-medial areas increased slightly but significantly from $1.9 \pm 8.0$ to $7.5 \pm 8.0 \mathrm{~ms}$. After a 180 -min partial occlusion of the LAICA, in the ischemic area, subepicardial MBF decreased from $0.62 \pm 0.17$ to $0.49 \pm 0.18 \mathrm{ml} \cdot \mathrm{g}^{-1} \cdot \mathrm{min}^{-1}$ and $e_{\mathrm{f}, \mathrm{e}}$ decreased from $-0.08 \pm 0.01$ to $-0.03 \pm 0.01$. No significant change in the difference in $t_{\mathrm{er}}$ between the normoxic and ischemic areas could be detected $(5.1 \pm 4.8$ and $5.2 \pm 5.8 \mathrm{~ms}$ in the control situation and after 180 -min partial occlusion, respectively). These findings indicate that in the ischemic epicardium 1) mechanical function is more affected than electrical impulse conduction and 2) delayed activation, if any, is accompanied by decreased instead of increased fiber strain, as found in the normoxic left ventricle.
\end{abstract}

regional cardiac mechanics; regional deformation; regional blood flow; coronary artery occlusion

FROM EXPERIMENTS FOCUSING ON either regional mechanical or electrical function, it is known that both functions are affected during myocardial ischemia $(4,8,14$, $15,18,20,26,29$ ). After occlusion of a coronary artery, systolic fiber shortening in the ischemic area is reduced within seconds. Within minutes, the ischemic fibers show a motion pattern characterized by lengthening during early systole, followed by delayed residual shortening after a decline in left ventricular pressure (20, 29). Ischemia also affects the electrophysiological properties of the cardiac cells $(8,14,15,18,26)$. Reductions in resting membrane potential and upstroke velocity and amplitude of the action potential have been reported (15). These changes influence considerably the conduction of the depolarization wave in the ischemic region. In canine $(4,26)$ as well as feline hearts $(18)$, coronary artery occlusion caused significant delays in the activation of the ischemic myocardium.

In the normoxic left ventricle, asynchronous electrical activation significantly affects regional mechanical function $(3,6,7,13,22)$. Regional fiber shortening and external work during the ejection phase were found to be lower in early-activated than in late-activated regions, with values ranging from 0 to $200 \%$ of that during sinus rhythm $(3,6,7)$.

Little is known about the relationship between the moment of electrical activation and regional mechanical function in the partially ischemic left ventricle. The present study was designed 1) to compare the sensitivity of regional electrical activation and mechanical function to the degree of ischemia and 2) to investigate the influence of electrical asynchrony on regional fiber strain, if any, during moderate and severe myocardial ischemia. Regional electrical activation time $\left(t_{\mathrm{ea}}\right)$, regional deformation, and regional myocardial blood flow were measured at the epicardium of the left ventricular free wall in open-chest dogs. Different degrees of ischemia were induced by total and sustained partial occlusion of the distal part of the left anterior interventricular coronary artery (LAICA). Measurements were performed at the epicardium because electrical conduction in the endocardially located Purkinje fibers is known to be hardly affected during ischemia $(14,26,33)$ and because most extreme asynchronies are to be expected at the (sub)epicardium, with myocardial conduction of the electrical signal. Moreover, at this site of the myocardium, measurements can be performed in a technically easy and accurate way.

\section{METHODS}

\section{Animal Preparation and Instrumentation}

Mongrel dogs of either sex, ranging in weight from 22 to 34 $\mathrm{kg}$, were premedicated with an intramuscular injection of Hypnorm ( $1 \mathrm{ml} / \mathrm{kg} ; 1 \mathrm{ml}$ Hypnorm contains $10 \mathrm{mg}$ fluanisone and $0.2 \mathrm{mg}$ fentanyl base). Anesthesia was induced with an intravenous injection of pentobarbital sodium $(10 \mathrm{mg} / \mathrm{kg})$ and was maintained with nitrous oxide $\left(33 \% \mathrm{O}_{2}-67 \%\right.$ nitrous oxide) and a continuous infusion of pentobarbital sodium (2 $\mathrm{mg} \cdot \mathrm{kg}^{-1} \cdot \mathrm{h}^{-1}$ ) after endotracheal intubation. Ventilation was kept constant with a positive-pressure respirator (Pulmomat, Dräger). The animal was placed on its right side, and body temperature was kept between 37.5 and $38.5^{\circ} \mathrm{C}$ by means of a thermostatically regulated heating pad. A standard limb-lead electrocardiogram (ECG) was recorded. Arterial blood samples 
were taken periodically to determine $\mathrm{PO}_{2}, \mathrm{PCO}_{2}, \mathrm{pH}$, oxygen saturation, and hemoglobin concentration (ABL 3, Radiometer). Sodium bicarbonate solution (4.2\%) was administered intravenously to adjust the acid-base balance when necessary.

The chest was opened through the left fifth intercostal space. After removal of the fifth rib, the pericardium was opened, and the heart was suspended in a pericardial cradle.

The LAICA was dissected free distal to the first diagonal side branch over a distance of $\sim 1.5 \mathrm{~cm}$, and an inflatable cuff with a width of $\sim 0.6 \mathrm{~cm}$ was placed around it (Fig. 1). A polyethylene catheter was inserted into a preferentially apical small side branch of the LAICA for the measurement of blood pressure distal to the stenosis (see below).

Polyethylene catheters were inserted into the left anterior interventricular vein and coronary sinus to obtain venous blood samples.

To assess regional myocardial blood flow, a Silastic catheter was placed in the left atrium for the injection of radioactively labeled microspheres, and a polyethylene catheter was inserted into the right brachial artery to obtain blood for the arterial reference sample.

Left ventricular cavity and ascending aortic pressures were measured with catheter-tip micromanometers (Millar $\mathrm{PC}-470$ ) inserted via the right brachial and right femoral artery, respectively. To enable pressure calibration during the experiment, the fluid-filled lumens of the catheter-tip micromanometers were connected to an external pressure transducer (Electromedics MS20) via three-way stopcocks. The third opening of the three-way stopcock was connected to a reference pressure level that was set at the right atrial level and used for all pressure measurements (2). Ascending aortic volume flow was measured with an electromagnetic flowmeter (Skalar Transflow 601).

ECG, pressure, and ascending aortic volume flow signals were continuously displayed on an oscilloscope (Knott). These signals were also recorded on a paper recorder (Schwarzer) and sampled $(200 \mathrm{~Hz})$ and digitized with a 16-channel 12-bit analog-to-digital card (DASH 16G2) connected to an MS-DOS personal computer (Tulip AT Compact). Sampling and analy-

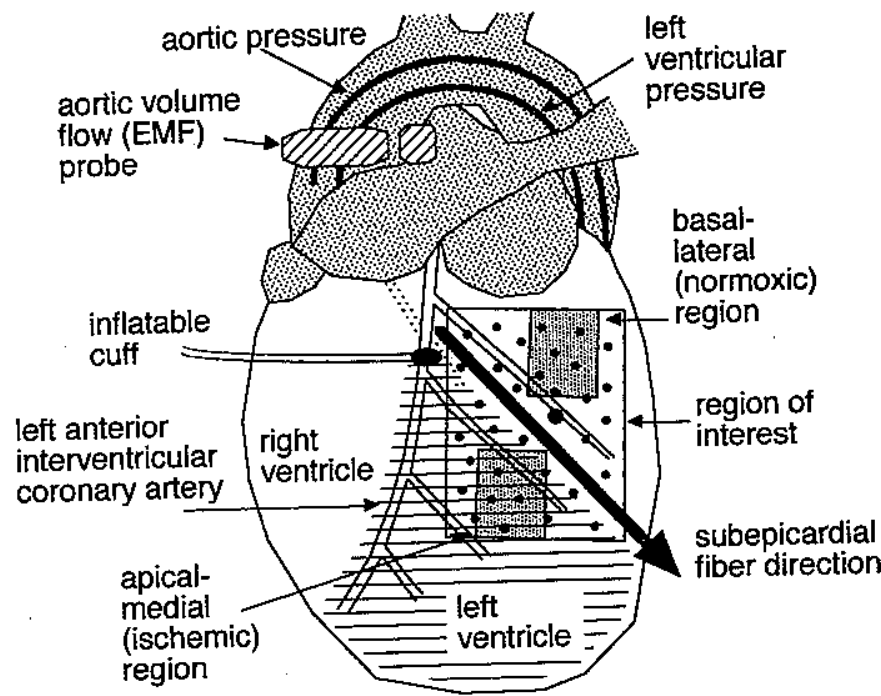

Fig. 1. Schematic representation of experimental setup. Solid circles within area of interest are optical markers attached to epicardial surface. Shaded area, ischemic area resulting from (partial) occlusion of distal part of left anterior interventricular coronary artery (LAICA). Shaded rectangles, regions for analysis of electrical activation and fiber strain in Fig. 4. EMF, electromagnetic flow probe. sis were performed with a software package (ASYST 3.0, MacMillan Software) and software developed in our laboratory.

\section{Determination of Hemodynamic Variables}

In the cardiac cycle, three events were determined. The end of the diastolic phase was defined as the moment before ejection at which the rate of change in left ventricular pressure $\left(\mathrm{dP}_{\mathrm{lv}} / \mathrm{d} t\right)$ exceeded $10 \mathrm{kPa} / \mathrm{s}$. The beginning of the ejection phase was determined by the moment at which left ventricular pressure exceeded aortic pressure. The duration of the ejection phase was determined from the aortic volume flow signal. From left ventricular pressure as a function of time, end-diastolic left ventricular pressure, maximum left ventricular pressure, and the maximum and minimum $\mathrm{dP}_{\mathrm{lv}} /$ $\mathrm{d} t$ were determined. In addition, the following hemodynamic variables were assessed: heart rate, maximum instantaneous ascending aortic volume flow, and ejected volume (time integral of ascending aortic volume flow).

\section{Mapping of Left Ventricular Epicardial Electrical Activation Pattern}

A 192-electrode brush $(44 \times 64 \mathrm{~mm})$ was used for the simultaneous recording of unipolar epicardial surface electrograms at the left ventricular anterior free wall. The grid spacing between the electrodes was $\sim 3.5 \mathrm{~mm}$. The electrode signals were recorded together with the left ventricular pressure and ECG signals. Off-line, in each electrogram, the moment with the steepest negative deflection was detected and labeled by a time mark, indicating the moment of regional activation of the tissue underneath the recording electrode (1). Mean regional $t_{\mathrm{ea}}$ was calculated by determining the time interval between the moment of maximum $\mathrm{dP}_{\mathrm{lv}} / \mathrm{d} t$ and the average moment of electrical activation within the regions used for deformation assessment (see Mapping of Left Ventricular Epicardial Fiber Strain) (6).

\section{Mapping of Left Ventricular Epicardial Fiber Strain}

For any moment in the cardiac cycle, natural strain in the direction of the subepicardial fibers $\left(e_{\xi}\right)$ was calculated from epicardial deformation by

$$
e_{\mathrm{f}}=\ln \frac{L_{\mathrm{f}}}{L_{\text {f,be }}}
$$

where $L_{\mathrm{f}}$ and $L_{\mathrm{f} \text {,be }}$ represent epicardial segment lengths along the subepicardial fiber direction at that specific moment and at the beginning of the ejection phase, respectively.

Two-dimensional epicardial deformation was determined with a video technique, as previously described in detail (24). In brief, $\sim 40$ white markers were attached with tissue glue (Histoacryl) to the epicardial surface of the left ventricular anterior wall at mutual distances of $\sim 6 \mathrm{~mm}$. The area covered with markers extended $3-4 \mathrm{~cm}$ in the circumferential and $4-5 \mathrm{~cm}$ in the base-to-apex directions (Fig. 1). A video camera (Sony AVC $32500 \mathrm{CE}$ ) with a $200-\mathrm{mm}$ teleobjective, positioned at an optical distance of $2.5 \mathrm{~m}$, was used to record the motion of the markers on a videotape recorder (Sony SL-C9ES, Betamax) at a speed of 50 frames/s. For convenience, the optical axis was deflected by a mirror mounted above the heart at an angle of $45^{\circ}$. Video-triggered xenon-flashlight illumination (Chadwick-Helmuth) was employed to prevent smearing of the images. The direction of the epicardial fibers and the long axis of the left ventricle as determined by visual inspection were indicated by a directed ruler and recorded on 
videotape (Fig. 1). To enable synchronization with hemodynamic data, a frequency-modulated left ventricular pressure signal was recorded on an audio channel of the videotape recorder.

After the experiment, 64 consecutive video frames were digitized and stored in a 2-MB digital video memory that was coupled to a computer (Laser AT). Marker tracers were determined with a singular value decomposition technique (16). The area covered with markers was subdivided in $5 \times 5$ subregions. Local epicardial deformation was determined from the marker traces in 16 overlapping regions, each consisting of $2 \times 2$ subregions by means of a least-squares criterion (24).

\section{Biochemical Analysis}

Lactate and $\mathrm{P}_{\mathrm{i}}$ in serum, as well as $\mathrm{pH}$ and oxygen extraction in whole blood, were determined as published previously (30). Differences between arterial samples and samples obtained from the coronary sinus and the left anterior interventricular vein were regarded to be representative of the normoxic basal-lateral and ischemic apical-medial parts, respectively, of the anterior free wall of the left ventricle.

\section{Determination of Regional Myocardial Blood Flow}

Regional myocardial blood flow was determined with radioactively labeled microspheres $(15.0 \pm 1.0 \mu \mathrm{m}$; NEN-TRAC, DuPont DeNemours) suspended in $10 \%$ dextran with $0.01 \%$ Tween 80 (20). The labels used were ${ }^{141} \mathrm{Ce},{ }^{113} \mathrm{Sn},{ }^{103} \mathrm{Ru}$, or ${ }^{95} \mathrm{Nb}$. At each determination, $3 \times 10^{6}$ microspheres were injected into the left atrium. An arterial reference sample was taken from the brachial artery at a rate of $20.7 \mathrm{ml} / \mathrm{min}$ with a Harvard withdrawal pump. Withdrawal of blood started $5 \mathrm{~s}$ before the injection of the microspheres and was continued for at least $1 \mathrm{~min}$.

After the experiment, the heart was fixed in $5 \%$ formaldehyde. Before dissection, nonmuscular structures such as fat and vessels at the epicardium and chordae tendinae were removed. Two transmural sections with an epicardial surface of $\sim 7 \times 7 \mathrm{~mm}$ were dissected from the left ventricular anterior free wall: a basal-lateral normoxic and an apicalmedial ischemic section. Each section was subdivided into a subepicardial and a subendocardial half, each of which was weighed. The radioactivity of the tissue and arterial blood samples was determined in a gamma counter (Packard multichannel analyzer). Regional myocardial blood flow in milliliters per gram per minute was calculated.

\section{Experimental Protocol}

In series $1(n=5)$, measurements were performed during the control period and after $15 \mathrm{~min}$ of total occlusion of the distal part of the LAICA. In series $2(n=11)$, measurements were performed during the control period and after $30,60,120$, and $180 \mathrm{~min}$ of moderate ischemia as induced by careful inflation of the occluder cuff around the LAICA (19). Mean coronary pressure distal to the stenosis was kept constant at $4.0 \mathrm{kPa}$ throughout the experimental period with a servo-motor pump with an autoregulating feedback system controlled by mean coronary artery pressure distal to the stenosis.

In both series 1 and 2 , measurements were performed as follows. Arterial, local venous, and coronary sinus blood samples were taken for chemical and blood gas analyses. Subsequently, microspheres were injected, and a reference arterial sample was taken for the calculation of regional myocardial blood flow. Hemodynamic variables and epicardial deformation were recorded simultaneously. Within $1 \mathrm{~min}$ thereafter, simultaneous recordings of hemodynamic variables and epicardial electrical activation were performed. In series 2 , regional myocardial blood flow was determined only during the control period and after 60 and $180 \mathrm{~min}$ of ischemia, whereas measurement of regional fiber strain was limited to four experiments.

Precise synchronization of hemodynamic data with deformation or electrical data was achieved by applying a correlation-interpolation technique to the left ventricular pressure signals obtained from the different recording devices (5). During the experiment, reproducible positioning of the electrode brush was obtained by visual matching of landmarks on the electrode brush with anatomic landmarks and/or video markers on the epicardial surface. Spatial matching of electrophysiological and deformation maps was enabled by a videotape recording of four white markers attached to the upper surface of the multielectrode brush (6).

The experiment was terminated by administration of an overdose of pentobarbital sodium. Within 5 min thereafter, the heart was excised, the atria were removed from the ventricles, and the ventricles were rinsed.

\section{Statistical Analysis}

The effect of partial and total occlusions of the distal part of the LAICA on hemodynamics, $t_{\text {ea }}$, deformation, biochemics, and regional blood flow was evaluated for statistical significance by comparing the data at the various intervals with the control values in the same animal. The sign test and the Wilcoxon matched-pairs signed rank test were used in series 1 ( $n=5$; total occlusion of the LAICA) and series $2(n=11$; partial occlusion of the LAICA), respectively. A value of $P<$ 0.05 was considered to be a significant difference. The data are presented as means \pm SD. Spatial gradients were determined with two-dimensional analysis.

\section{RESULTS}

\section{Series 1}

Normoxia. During normoxia, regional deformation and electrical activation were almost homogeneously distributed over the epicardium of the left ventricular anterior free wall (Fig. 2). No difference in myocardial blood flow, either between the subepicardium and the subendocardium or between the normoxic area and the area expected to become ischemic, could be detected (Table 1).

Ischemia. Total occlusion of the distal part of the LAICA caused ischemia, as indicated by the decrease in $\mathrm{pH}$ in the coronary effluent of the ischemic area (Table 2). The oxygen extraction fraction in the ischemic area increased from 67 to $81 \%$. In the normoxic areas, the oxygen extraction fraction remained unchanged.

Hemodynamic performance decreased after total occlusion of the distal part of the LAICA. Compared with the control values, end-diastolic left ventricular pressure was increased, whereas maximum left ventricular pressure, mean poststenotic coronary perfusion pressure, maximum aortic volume flow, and maximum and minimum $\mathrm{dP}_{\mathrm{lv}} / \mathrm{d} t$ values were reduced (Table 3 ).

Total occlusion of the distal part of the LAICA reduced subepicardial and subendocardial myocardial blood flows in the apical-medial regions of the area under investigation from $0.86 \pm 0.36$ to $0.18 \pm 0.11$ $\mathrm{ml} \cdot \mathrm{g}^{-1} \cdot \mathrm{min}^{-1}$ and from $0.78 \pm 0.24$ to $0.04 \pm 0.02$ 
Fig. 2. Maps of regional electrical activation time and subepicardial fiber strain during isovolumic contraction phase $\left(e_{\mathrm{f}, \mathrm{ic}}\right)$ and ejection phase $\left(e_{\mathrm{f}, \mathrm{e}}\right)$ during control period and after $15 \mathrm{~min}$ of total occlusion (occl.) of LAICA. Data are averaged over experiments. Electrical activation time is referred to moment of maximum rate of change of left ventricular pressure $\left(\mathrm{dP}_{\mathrm{lv}} / \mathrm{d} t\right)$. Note that its value in late-activated regions is less negative than that in early-activated regions. Detailed maps obtained with 192-electrode brush were reduced to a $4 \times 4$ matrix. Boundaries between different degrees of shading indicate time intervals of $5 \mathrm{~ms}$. In maps depicting fiber strain, these boundaries mark intervals of 0.05 . Arrows, gradients.

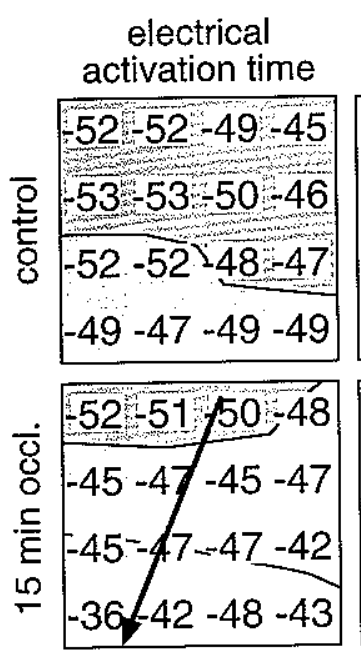

fiber strain during isovolumic phase

\begin{tabular}{|rrrr}
-.02 & -.03 & -.04 & -.03 \\
-.03 & -.03 & -.03 & -.03 \\
-.03 & -.03 & -.02 & -.03 \\
-.02 & -.02 & -.02 & -.02
\end{tabular}

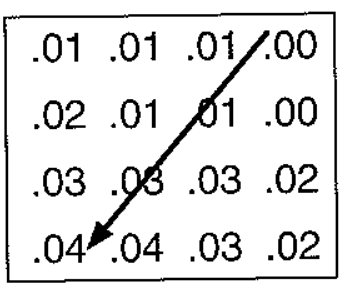

fiber strain during ejection phase

\begin{tabular}{|c|}
\hline$-.10-.10]-10-.11$ \\
\hline$-.10[-.10]-.10]-10$ \\
\hline$-.10-.11=.12$ \\
\hline$-10|-.11|-11 \mid$ \\
\hline
\end{tabular}

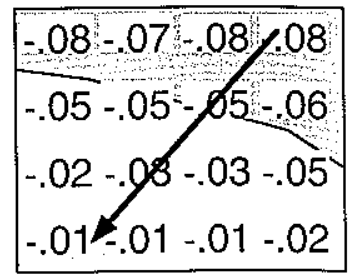

$\mathrm{ml} \cdot \mathrm{g}^{-1} \cdot \mathrm{min}^{-1}$, respectively. The ratio of subendocardial to subepicardial blood flow decreased from $0.96 \pm 0.14$ to $0.25 \pm 0.12$ (Table 1 ). The $t_{\mathrm{ea}}$ and $e_{\mathrm{f}}$ values changed concomitantly (Fig. 2). The delay in $t_{\mathrm{ea}}$ between the normoxic basal-lateral and ischemic apical-medial areas increased from $1.9 \pm 8.0$ to $7.5 \pm 8.0 \mathrm{~ms}$ (for position of these areas, see Fig. 1). In the ischemic apical-medial region, fiber strain during the isovolumic contraction phase $\left(e_{\mathrm{f}, \mathrm{ic}}\right)$ changed from $-0.02 \pm 0.01$ to $+0.04 \pm 0.03$ and during the ejection phase $\left(e_{\mathrm{r}, \mathrm{e}}\right)$ from $-0.11 \pm 0.02$ to $-0.01 \pm 0.01$.

\section{Series 2}

Normoxia. The findings on the distribution of myocardial blood flow (Table 1) and regional fiber strain (Fig. 3 ) were similar to those in series 1 . However, electrical activation maps showed a gentle gradient. On average, the basal-lateral area was activated slightly $(5 \mathrm{~ms})$ before the apical-medial area.

Ischemia. HEMODYNAMICS. Poststenotic coronary artery pressure was kept constant at $4.0 \mathrm{kPa}$, with $<0.5$ $\mathrm{kPa}$ intraindividual variation throughout the experi- mental period and $<1.0 \mathrm{kPa}$ variation between animals (Table 3). Ejected volume, maximum rate of aortic volume flow, and maximum and minimum $\mathrm{dP}_{\mathrm{lv}} / \mathrm{d} t$ values were decreased after impairment of coronary flow. Maximum left ventricular pressure was decreased after 180 min of partial occlusion.

BLOOD GASES AND BIOCHEMICAL VARIABLES. By keeping mean poststenotic pressure at $\sim 4.0 \mathrm{kPa}$, the related impairment of coronary inflow caused ischemia, as indicated by the decrease in $\mathrm{pH}$, and the release of lactate and $P_{i}$ into the coronary effluent of the ischemic area. Oxygen extraction was increased in the ischemic area (Table 2).

REGIONAL MYOCARDIAL BLOOD FLOW. Partial occlusion of the distal part of the LAICA induced a redistribution of myocardial blood flow. Subepicardial blood flow in the nonischemic area was increased after 60 and 180 min of ischemia, whereas subendocardial blood flow did not change (Table 1). As a consequence, the ratio of subendocardial to subepicardial blood flow decreased from 1.10 to 1.00 and 1.02 after 60 and $180 \mathrm{~min}$ of ischemia, respectively. In the ischemic area, subepicar-

Table 1. Regional myocardial blood flow in Epi and Endo layers of left ventricular wall and Endo/Epi during control period and after occlusion of LAICA

\begin{tabular}{|c|c|c|c|c|c|}
\hline & \multirow{2}{*}{\multicolumn{2}{|c|}{ Series 1}} & \multicolumn{3}{|c|}{ Series 2} \\
\hline & & & \multirow[b]{2}{*}{$\begin{array}{l}\text { Control } \\
(n=11)\end{array}$} & \multicolumn{2}{|c|}{ Partial occlusion } \\
\hline & $\begin{array}{c}\text { Control } \\
(n=5)\end{array}$ & $\begin{array}{c}\text { 15-min Occlusion } \\
(n=5)\end{array}$ & & $\begin{array}{l}60 \min \\
(n=7)\end{array}$ & $\begin{array}{l}180 \min \\
(n=11)\end{array}$ \\
\hline \multicolumn{6}{|c|}{ Normoxic region } \\
\hline Epi & $0.80 \pm 0.32$ & $0.92 \pm 0.25^{*}$ & $0.64 \pm 0.24$ & $0.73 \pm 0.26$ & $0.70 \pm 0.23$ \\
\hline Endo & $0.91 \pm 0.39$ & $0.72 \pm 0.24$ & $0.68 \pm 0.21$ & $0.71 \pm 0.23$ & $0.71 \pm 0.24$ \\
\hline Endo/Epi & $1.13 \pm 0.16$ & $0.81 \pm 0.28 \%$ & $1.10 \pm 0.22$ & $1.00 \pm 0.29 \%$ & $1.02 \pm 0.14^{*}$ \\
\hline \multicolumn{6}{|c|}{$\begin{array}{l}\text { Endo/Epi } \\
\text { Ischemic region }\end{array}$} \\
\hline Epi & $0.86 \pm 0.36$ & $0.18 \pm 0.09$ & $0.62 \pm 0.17$ & $0.58 \pm 0.13$ & $0.49 \pm 0.18^{\circ}$ \\
\hline Endo & $0.78 \pm 0.24$ & $0.04 \pm 0.02^{*}$ & $0.65 \pm 0.19$ & $0.35 \pm 0.15^{*}$ & $0.31 \pm 0.16^{*}$ \\
\hline Endo/Epi & $0.96 \pm 0.14$ & $0.25 \pm 0.12^{*}$ & $1.07 \pm 0.23$ & $0.60 \pm 0.22^{*}$ & $0.63 \pm 0.24^{*}$ \\
\hline
\end{tabular}

Values are means $+\mathrm{SD}$ in $\mathrm{ml} \cdot \mathrm{g}^{-1} \cdot \mathrm{min}^{-1} ;$ nos. in parentheses, no. of dogs. LAICA, left anterior interventricular coronary artery; Epi, outer (subepicardial); Endo, inner (subendocardial); Endo/Epi, ratio of Endo to Epi; series 1, total occlusion of LAICA; series 2, partial occlusion of LAICA. * Significantly different from control withị same series by sign test and Wilcoxon signed rank test for series 1 and 2 , respectively, $P<$ 0.05 . 
Table 2. Values of chemical variables in arterial, local venous, and coronary sinus blood samples for series 1 and 2

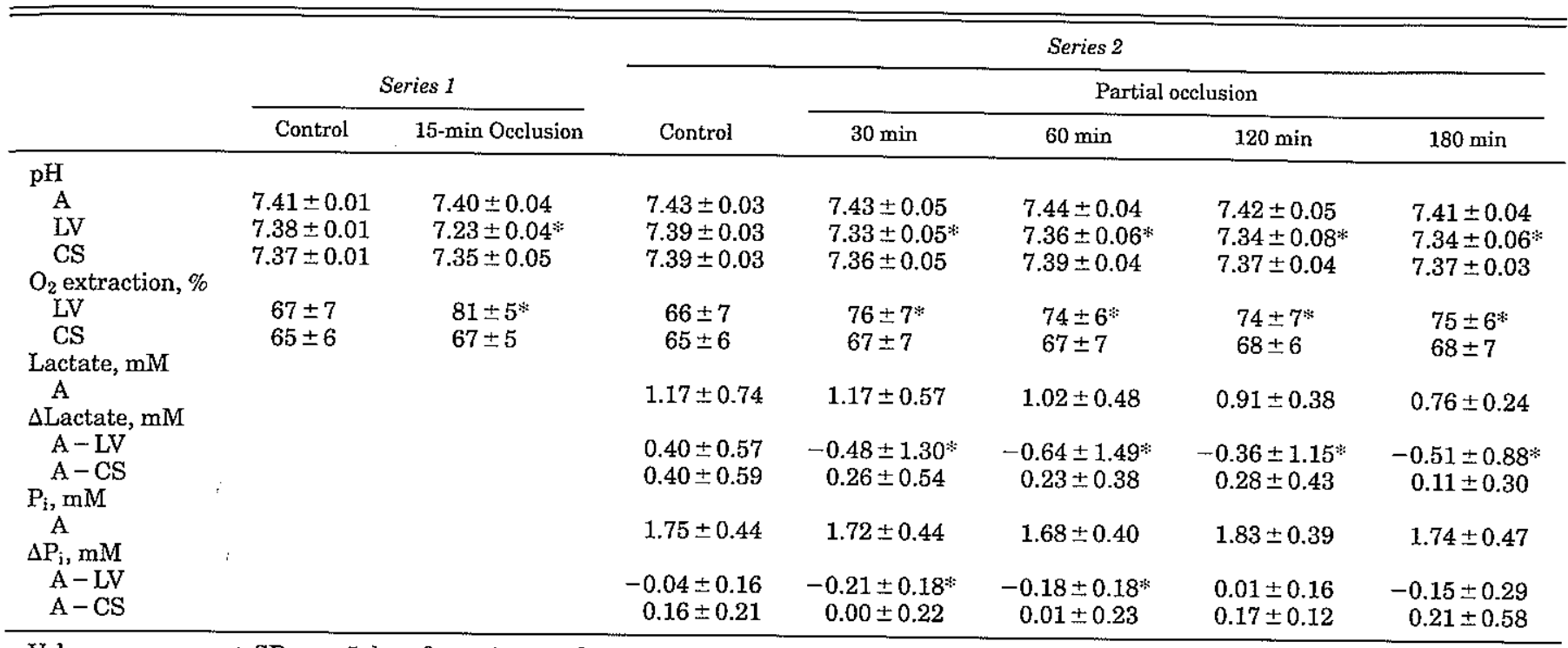

Values are means $\pm \mathrm{SD} ; n=5$ dogs for series 1 and $n=11$ dogs for series 2 except $n=7$ dogs for difference in $(\Delta)$ lactate and $\Delta \mathrm{P}_{\mathrm{i}}$. $\mathrm{A}$, arterial; LV, local venous; CS, coronary sinus. : Significantly different from control by sign test and Wilcoxon signed rank test for series 1 and 2 , respectively, $P<0.05$.

dial blood flow was decreased at $180 \mathrm{~min}$ of ischemia, whereas subendocardial blood flow was decreased at both 60 and $180 \mathrm{~min}$ of ischemia. The ratio of subendocardial to subepicardial blood flow decreased from 1.07 to 0.60 and 0.63 after 60 and $180 \mathrm{~min}$ of partial occlusion, respectively.

REGIONAL ELECTRICAL ACTIVATION. Partial occlusion of the LAICA caused only minor changes in electrical activation of the area under investigation. Mean epicardial $t_{\mathrm{ea}}$ values, as averaged over the experiments ( $n=$ 11), are presented in Fig. 3. During normoxia and ischemia, the basal regions of the area under investigation were activated first, followed by the apical-lateral region and the apical-medial region in that order. The delay in $t_{\mathrm{ea}}$ between the normoxic basal-lateral and ischemic apical-medial areas did not change during the course of the experiment, being $5.1 \pm 4.8,5.0 \pm 3.8$,
$7.2 \pm 4.8,4.6 \pm 4.9$, and $5.2 \pm 5.8 \mathrm{~ms}$ during the control period and at $30,60,120$, and $180 \mathrm{~min}$ of ischemia, respectively (Fig. 4).

REGIONAL FIBER STRAIN. After partial occlusion of the LAICA, the degree of fiber strain was inhomogeneously distributed. In the basal regions, the subepicardial fiber-shortening pattern hardly changed compared with the control situation. Only during the ejection phase was fiber shortening slightly decreased (Fig. 3). In the ischemic apical-medial area, however, fibers lengthened during the isovolumic contraction phase, and during the ejection phase, fibers shortened less than in the nonischemic area. As a result, during both phases of the cardiac cycle, a spatial gradient in the degree of fiber shortening could be noticed during partial occlusion of the LAICA (Fig. 3). This gradient is also depicted in Fig. 4, which presents the time course of $e_{\mathrm{f}, \mathrm{ic}}$

Table 3. Hemodynamic variables during control period and occlusion of LAICA for series 1 and 2

\begin{tabular}{|c|c|c|c|c|c|c|c|}
\hline & \multirow{2}{*}{\multicolumn{2}{|c|}{ Series 1}} & \multicolumn{5}{|c|}{ Series 2} \\
\hline & & & \multirow[b]{2}{*}{ Control } & \multicolumn{4}{|c|}{ Partial occlusion } \\
\hline & Control & 15-min Occlusion & & $30 \min$ & $60 \mathrm{~min}$ & $120 \min$ & $180 \min$ \\
\hline $\mathrm{HR}$, beats/min & $86.5 \pm 11.1$ & $92.0 \pm 16.9$ & $93.3 \pm 16.1$ & $102.2 \pm 16.8$ & $97.3 \pm 17.5$ & $95.3 \pm 17.7$ & $96.8 \pm 10.2$ \\
\hline LVEDP, $\mathrm{kPa}$ & $1.2 \pm 0.2$ & $1.9 \pm 0.3^{*}$ & $1.0 \pm 0.4$ & $1.1 \pm 0.5$ & $1.2 \pm 0.6$ & $1.1 \pm 0.5$ & $1.2 \pm 0.5$ \\
\hline$\underline{P}_{l v, \max }, \mathrm{kPa}$ & $13.9 \pm 1.2$ & $12.1 \pm 1.8^{*}$ & $13.3 \pm 1.5$ & $13.3 \pm 1.8$ & $13.0 \pm 1.8$ & $12.4 \pm 1.0$ & $12.0 \pm 1.0 *$ \\
\hline$\overline{\mathrm{P}}_{\text {cor }}, \mathrm{kPa}$ & $10.4 \pm 1.6$ & $2.6 \pm 0.9 *$ & $10.1 \pm 1.9$ & $4.0 \pm 0.6 *$ & $4.0 \pm 0.7^{*}$ & $3.9 \pm 0.4^{*}$ & $4.0 \pm 0.5^{*}$ \\
\hline$V_{\mathrm{c}}, \mathrm{ml}$ & $24.2 \pm 3.3$ & $26.4 \pm 4.6$ & $22.5 \pm 4.4$ & $18.9 \pm 5.4^{*}$ & $19.3 \pm 4.9^{*}$ & $19.1 \pm 5.2^{*}$ & $18.7 \pm 5.3^{\%}$ \\
\hline$\dot{\mathrm{Q}}_{\mathrm{Ao, \operatorname {max }}}, \mathrm{ml} / \mathrm{s}$ & $227.3 \pm 40.2$ & $201.1 \pm 34.7^{*}$ & $212.2 \pm 44.2$ & $176.1 \pm 42.1^{*}$ & $178.2+35.8^{8}$ & $166.6 \pm 26.0 \%$ & $164.7 \pm 25.6^{*}$ \\
\hline $\mathrm{dP}_{\mathrm{lv}} / \mathrm{d} t_{\max }, \mathrm{kPa} / \mathrm{s}$ & $197.0 \pm 25.8$ & $163.9 \pm 34.6^{*}$ & $184.0 \pm 23.5$ & $172.7 \pm 18.0^{*}$ & $169.7 \pm 23.1^{*}$ & $157.0 \pm 27.1^{*}$ & $151.5 \pm 25.3^{\text {* }}$ \\
\hline $\mathrm{dP}_{\mathrm{lv}} / \mathrm{d} t_{\min }, \mathrm{kPa} / \mathrm{s}$ & $-207.5 \pm 27.6$ & $-135.9 \pm 28.3^{*}$ & $-178.8 \pm 32.2$ & $-176.9 \pm 31.9$ & $-167.9 \pm 33.9^{*}$ & $-161.2 \pm 19.5^{*}$ & $-145.1 \pm 13.2 \%$ \\
\hline
\end{tabular}

\footnotetext{
Values are means $\pm \mathrm{SD} ; n=5$ dogs for series 1 and $n=11$ dogs for series 2 . HR, heart rate; LVEDP, left ventricular end-diastolic pressure; $\mathrm{P}_{\mathrm{lv}, \max }$, maximum left ventricular pressure; $\overline{\mathrm{P}}_{\mathrm{cor}}$, mean poststenotic coronary artery pressure; $\mathrm{V}_{\mathrm{c}}$, ejected volume; $\dot{\mathrm{Q}}_{\mathrm{Ab}, \max }, \mathrm{maximum}_{\mathrm{m}}$ aortic volume flow; $\mathrm{dP}_{\mathrm{lv}} / \mathrm{d} t_{\max }$ and $\mathrm{dP}_{\mathrm{lv}} / \mathrm{d} t_{\min }$, maximum and minimum rate of change in left ventricular pressure, respectively. $*$ Significantly different from control by sign test and Wilcoxon signed rank test for series 1 and 2 , respectively, $P<0.05$.
} 
Fig. 3. Maps of regional electrical activation time $(n=11)$ and regional subepicardial fiber strain during isovolumic contraction phase $(n=4)$ and ejection phase $(n=4)$ as averaged over experiments with 3-h partial occlusion (isch.) of LAICA. Successive rows show results obtained during control period and after $30,60,120$, and $180 \mathrm{~min}$ of partial occlusion of LAICA. Arrows, gradients.

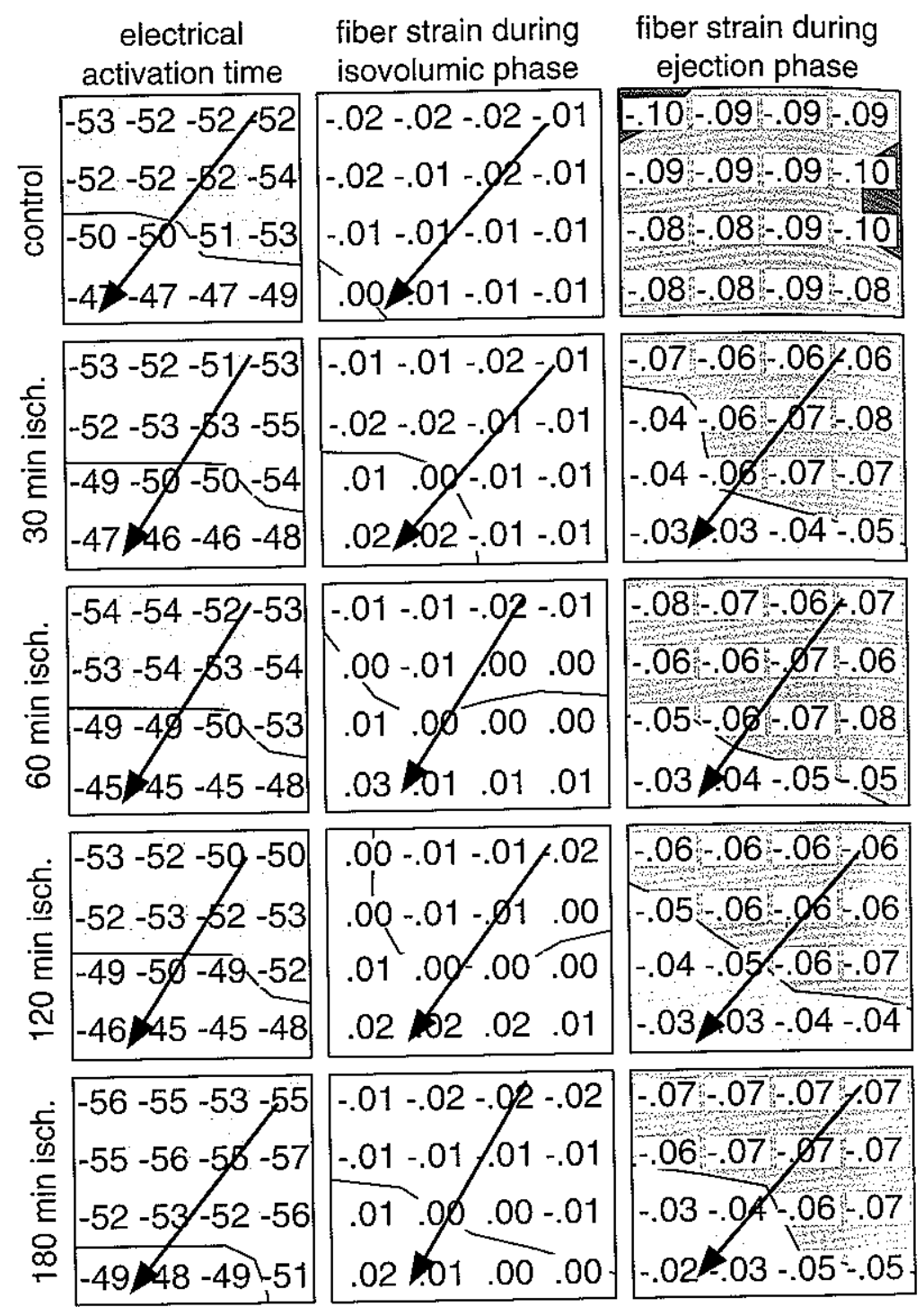

(middle) and $e_{\mathrm{f}, \mathrm{e}}$ (bottom) for the normoxic and ischemic areas, respectively.

RELATIONSHIP BETWEEN ELECTRICAL ACTIVATION TIME AND FIBER STRAIN. Figure 5 shows the regional subepicardial $e_{\mathrm{f}, \mathrm{e}}$ plotted as a function of the regional $t_{\mathrm{ea}}$ (in $\mathrm{ms}$ ). In a previous study of the normoxic left ventricle, using epicardial pacing at the left ventricular free wall, the left ventricular apex, or the right ventricular outflow tract as an intervention to obtain electrical asynchronous activation, we showed that the relationship between $e_{\mathrm{f}, \mathrm{e}}$ and $t_{\mathrm{ea}}$ could be approximated by the linear equation $e_{\mathrm{f}, \mathrm{e}}=a \cdot t_{\mathrm{ea}}+b$, in which $a=-3.46 \pm 0.73 \mathrm{~s}^{-1}$ and $b=-0.28 \pm 0.05(6)$. This relationship is depicted by the straight lines in Fig. 5 . The slope of the relationship reflects the increase in $e_{\mathrm{f}, \mathrm{e}}$ when the time difference between the moment of regional electrical activation and the moment of maximum $\mathrm{dP}_{\mathrm{lv}} / \mathrm{d} t$ decreases. In Fig. 5 , the symbols denote data from all 16 regions as averaged over the experiments. Data obtained during normoxia form a cluster on the line found in our previous study. During acute total (Fig. 5A) or prolonged partial occlusion of the LAICA (Fig. $5 B$ ), however, data points deviated from the previously found relationship and are shifted right upward, indicating that delayed electrical activation is associated with decreased $e_{\mathfrak{r}, \mathrm{e}}$.

\section{DISCUSSION}

This is the first study that investigated the relationship between $t_{\mathrm{ea}}$ and deformation in the ischemic left ventricle. The findings indicate that, whereas in the ischemic epicardium, regional fiber shortening during the ejection phase is considerably reduced during total as well as partial occlusion of the LAICA, epicardial electrical activation of the ischemic epicardium is only significantly delayed during total coronary occlusion. This indicates that in the epicardium mechanical function is more sensitive to ischemia than is electrical activation. It was also found that, whereas in the normoxic left ventricles late-activated fibers show en- 

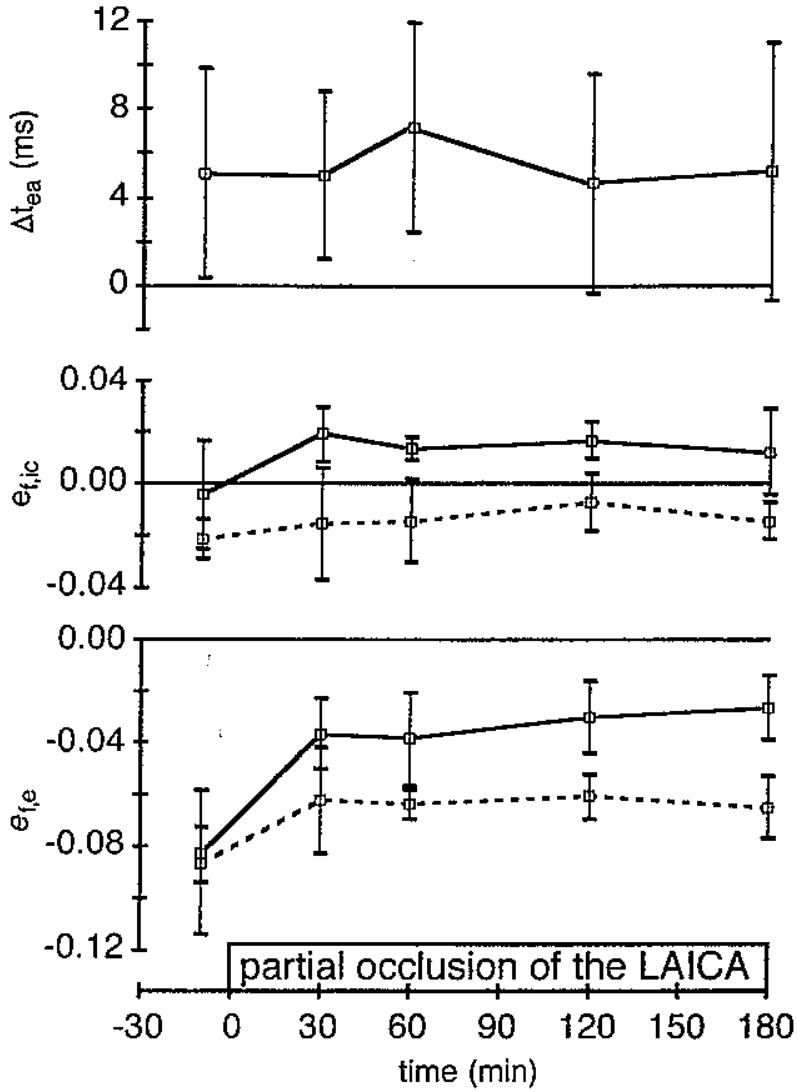

Fig. 4. Time course of delay in electrical activation time in ischemic apical-lateral area with respect to normoxic basal-medial area $\left(\Delta t_{\mathrm{ea}}\right.$; $n=11)$ and to fiber strain during isovolumic phase $\left(e_{f, i c} ; n=4\right)$ and ejection phase $\left(e_{\mathrm{f}, \mathrm{e}} ; n=4\right)$. For $e_{\mathrm{f}, \mathrm{e}}$ and $e_{\mathrm{f}, \mathrm{ic}}$, dashed and solid lines refer to normoxic and ischemic areas, respectively.

hanced shortening during the ejection phase (6), in the partially ischemic left ventricle, late-activated fibers show decreased fiber shortening during this phase of the cardiac cycle.

In the asynchronously activated normoxic heart, it was found that early-activated fibers contract early and with a high shortening velocity during the isovolumic phase, causing a prestretch in serially connected as yet nonactivated fibers. The prestretch induces an increase in contractile force of these fibers. When finally activated, the late-activated fibers shorten vigorously during the ejection phase, counteracting further contraction of the early-activated fibers, which are likely to be partly deactivated due to the period of fast shortening during the isovolumic phase. As a result, $e_{\mathrm{f}, \mathrm{e}}$ is considerably less in early-activated than in late-activated regions. Based on the linear relationship between $t_{\mathrm{ea}}$ and the amount of $e_{\mathrm{f}, \mathrm{e}}$ as found in the normoxic situation, one would expect that an average electrical delay of $\sim 7.5 \mathrm{~ms}$ during acute total occlusion of the LAICA produces an increase in $e_{\mathrm{f}, \mathrm{e}}$ of -0.025 , thereby increasing local oxygen requirements $(6,7)$. The present study, however, indicates that ischemic conditions cause the extent of $e_{\mathrm{f}, \mathrm{e}}$ to deviate from its relationship with the moment of electrical activation as present during normoxia (Fig. 5). The delayed activated ischemic fibers show lengthening during early systole, followed by some residual shortening after a decline in left ventricular pressure. This shortening pattern was also found in previous measurements in ischemic myocardium $(9,10$, 20,29 ) and is most likely due to mechanical interaction between strongly (nonischemic) and weakly contracting (ischemic) fibers (32). Therefore, the metabolic disturbances in ischemic myocardium $(17,23,30,34)$ are the major determinants of regional mechanical function. Our findings indicate that, although the contraction pattern of the ischemic left ventricle is often referred to as being "asynchronous" or "dyssynchronous" $(11,12)$, it might be better to refer to an "inhomogeneous" contraction pattern because fiber shortening is affected by ischemia independent of the effects on electrical activation.

Total and partial occlusions of the LAICA had different effects on epicardial electrical activation: a small but significant delay in electrical activation of the ischemic region during total LAICA occlusion and no change during partial LAICA occlusion. The reduction in regional fiber shortening during the ejection phase, however, was similar for both experimental conditions, indicating that mechanical function is more sensitive to ischemia than electrical impulse conduction. Because epicardial breakthrough of electrical activation during
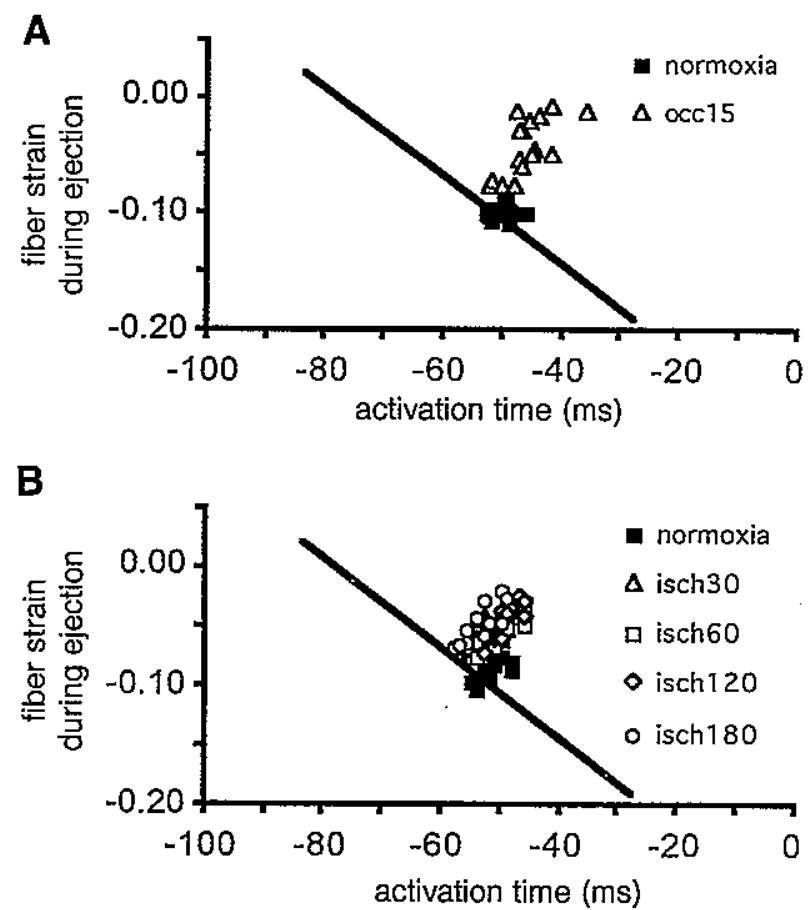

Fig. 5. Regional subepicardial $e_{\mathrm{f}, \mathrm{e}}$ plotted as a function of $t_{\mathrm{ea}}$. occ15, 15-min total LAICA occlusion; isch 30 , isch60, isch120, and isch180, $30,60,120$, and $180 \mathrm{~min}$, respectively, of partial LAICA occlusion. Solid lines, relationship found in normoxic left ventricle during asynchronous electrical activation induced by epicardial pacing $\left(e_{\mathrm{f}, \mathrm{e}}=\right.$ $a \cdot t_{\mathrm{ca}}+b$, in which $a=-3.46 \pm 0.73 \mathrm{~s}^{-1}$ and $\left.b=-0.28 \pm 0.05\right)(6)$. Symbols denote data from all 16 regions as averaged over experiments. Data obtained during normoxia form a cluster on line found in our previous study (6). During acute total $(A)$ or prolonged partial occlusion $(B)$ of LAICA, however, data points deviated from previously found relationship and are shifted right upward, indicating that delayed electrical activation was accompanied with decreased fiber strain. 
sinus rhythm can occur at different sites, varying from the basal to the apical regions $(21,22,28)$ and the experimental models and methods of series 1 and 2 are similar, the differences in electrical activation patterns in the control situation of series 1 and 2 are thought to be coincidental. The differences in the delay of electrical activation during total and partial LAICA occlusions can be explained by the different degrees of reduction in epicardial blood flow in the two series (Table 1). It has been reported that conduction is disturbed only in areas with blood flows $<25 \%$ of the control value, e.g., between 0.05 and $0.30 \mathrm{ml} \cdot \mathrm{g}^{-1} \cdot \mathrm{min}^{-1}$ (27). The observation that epicardial electrical activation was not affected by partial occlusion of the LAICA is supported by experiments on canine hearts in which the main circumflex coronary artery was partially occluded (25). In these experiments, a decrease in coronary blood flow of $50 \%$ did not change the epicardial conduction time from the normoxic to the ischemic area. In contrast, epicardial fiber shortening in the ischemic regions significantly decreased at flow reductions of only $20 \%$ (Table 1, Fig. 3). This is in agreement with previous studies $(9,20,31)$. These observations indicate that during ischemia metabolic conditions related to electrical impulse conduction (extracellular $\mathrm{K}^{+}$and $\mathrm{Na}^{+}$) do not change as dramatically and persistently as do the conditions determining contractile function (energy-rich phosphates and $\mathrm{pH}$ ). However, because disturbances in biochemical conditions, such as oxygen supply, hydrolysis of creatine phosphate, and the accumulation of hydrogen ions and $P_{i}$, may not be severe enough during moderate ischemia to explain the early contractile failure of the epicardial fibers (20), additional mechanisms may be considered. One responsible mechanism might be tethering of epicardial layers to more severely compromised endocardial layers either structurally or functionally $(9,20,31)$. The role of tight interconnections between the various layers is less probable because it has been shown that, within the first $30 \mathrm{~s}$ of ischemia, fiber shortening in the inner layers is depressed without a significant decrease in fiber shortening in the outer layers (20). A functional dependency of the various layers can be hypothesized as follows. Because ischemia forces the inner layers to decrease their mechanical performance, the entire building up of left ventricular pressure has to be performed by the remaining part of the wall, resulting in an increase in fiber stress and a decrease in fiber shortening.

It is possible that we did not detect the earliest and latest activated regions and, hence, underestimated the maximum delay in electrical activation because, in our experiments, measurements of electrical activation were confined to the lateral free wall. Despite this limitation, the average maximal delay of $16 \mathrm{~ms}$ found in the present study (Fig. 2) is in accordance with the results reported in the literature $(18,25,26)$. In canine hearts with total occlusion of the LAICA $1-2 \mathrm{~cm}$ distal to the origin of the anterior septal artery, total $t_{\mathrm{ea}}$ at the ischemic epicardium during right ventricular outflowtract pacing was increased by $10 \%$ compared with the normoxic control situation (26). In the latter study, total time was defined as the difference in time between the moment of the stimulation artifact and the end of electical activity in the local bipolar electrogram in the remote ischemic myocardium. Although no absolute data in milliseconds are available, it can be estimated that electrical activation is delayed by an average of 12 $\mathrm{ms}$ maximum, because the left ventricle is known to be activated within at least $120 \mathrm{~ms}$ after stimulation at the right ventricular outflow tract $(6,21)$. Although in canine hearts electrical activation has been reported to be delayed up to $250 \mathrm{~ms}$ (4), it should be noted that this conforms to sustained desynchronized electrical activity in local myocardial areas after the onset of activation. Because we use a different definition of electrical delay, data are incomparable. In feline hearts, after 5 or 10 min of total occlusion of the LAICA proximal to all branch points, total ventricular activation time during sinus rhythm was found to be delayed from $25 \pm 2$ to $64 \pm 6$ and $63 \pm 8 \mathrm{~ms}$, respectively (18). Beats preceding a single premature ventricular contraction that was initiated by intramural reentry were characterized by a markedly increased conduction delay (149 \pm $7 \mathrm{~ms}$ ), with terminal activation in the apex. As in our study, the increase in total activation time was not reflected by an increase in the QRS interval, demonstrating that the QRS complex of surface limb leads is insensitive to delayed activation of a small volume of myocardium.

It is likely that the activation of the deeper layers in the ischemic part of the area under investigation is relatively unaffected (26). Slowing down of conduction may be absent in subendocardial Purkinje layers despite a significant decrease in coronary blood flow (14). Resting membrane potential may not decrease precipitously due to diffusion of oxygen from the cavitary blood into the subendocardium (33). If so, lateral spread of depolarization from adjacent normally perfused epicardium is unlikely to cause the epicardium of the ischemic regions to be activated sooner than the endocardium. The delay in electrical activation of the ischemic myocardium, if any, is due to impairment of transmural conduction and will increase from the endocardium to the epicardium. Therefore, epicardial electrical activation measurements, as performed in this study, should have detected this delay in electrical activation, if present. So, in the myocardial layer most sensitive to delayed electrical conduction and least sensitive to mechanical failure, the latter proved to be more pronounced, underscoring the difference in sensitivity.

It could be argued that our deformation measurements should have been performed earlier after partial occlusion of the LAICA to detect any influence of delayed electrical activation because in pig hearts made regionally ischemic by total coronary artery occlusion, the delay in electrical activation of the ischemic subepicardium has been reported to diminish after 10-30 min due to the reappearance of transmembrane potentials in previously unresponsive cells (15). However, the delay in electrical activation of the ischemic apical-lateral area with respect to the normoxic 
basal-lateral area did not change after 5,10 , and 20 min of partial occlusion of the LAICA $(6.6 \pm 5.8,6.5 \pm$ 4.5 , and $3.4 \pm 3.4 \mathrm{~ms}$, respectively) compared with the control situation $(5.1 \pm 4.8 \mathrm{~ms})$.

During partial occlusion of the LAICA, part of the myocardium became ischemic, as indicated by the release of lactate (34) and $P_{i}$, due to a breakdown of energy-rich phosphates (17) from the ischemic area. The time course of arterial-local coronary venous differences in lactate and $\mathrm{P}_{\mathrm{i}}$ content is in accordance with those observed in previous studies $(23,30)$, which reported a maximum release of both substances within $15 \mathrm{~min}$ after the induction of a partial occlusion of the LAICA. In these studies, the LAICA was partially occluded for $120 \mathrm{~min}$ while the mean poststenotic pressure was kept constant at $\sim 3.0 \mathrm{kPa}$. The release of lactate remained increased during the total course of the experiment, whereas the release of $P_{i}$ was not increased anymore after $60 \mathrm{~min}$ of partial occlusion. The higher mean poststenotic pressure, as used in our study, resulted in a less severe degree of ischemia, as indicated by the less pronounced release of both lactate and $P_{\mathrm{i}}$.

Two major conclusions can be drawn. First, epicardial mechanical function is more sensitive to ischemia than epicardial electrical-impulse conduction. This indicates that measurement of myocardial deformation may be a more sensitive tool to detect ischemia than electrophysiological measurements. Second, the relationship between $t_{\mathrm{ea}}$ and the amount of $e_{\mathrm{f}, \mathrm{c}}$ is strikingly different in normoxic and ischemic myocardia. Whereas in the normoxic left ventricle late-activated fibers show enhanced shortening during the ejection phase, in the partially ischemic left ventricle they show decreased fiber shortening. This indicates that metabolic disturbances are more important determinants of mechanical performance in the ischemic myocardium than are disturbances in electrical-impulse conduction.

This work was supported by the Netherlands Organization for Scientific Research Grant 900-516-091.

Address for reprint requests: F. W. Prinzen, Dept. of Physiology, Cardiovascular Research Institute Maastricht, Univ. of Maastricht, PO Box 616, 6200 MD Maastricht, The Netherlands.

Received 28 August 1995; accepted in final form 3 April 1996.

\section{REFERENCES}

1. Allessie, M. A., A. P. G. Hoeks, G. M. L. Schmitz, and R. S. Reneman. On-line mapping system for the visualization of the electrical activation of the heart. Int. J. Card. Imaging 2: 59-63, 1986.

2. Arts, T., P. C. Veenstra, and R. S. Reneman. Epicardial deformation and left ventricular wall mechanics during ejection in the dog. Am. J. Physiol. 243 (Heart Circ. Physiol. 12): H379-H390, 1982.

3. Badke, F. R., P. Boinay, and J. W. Covell. Effect of ventricular pacing on regional left ventricular performance in the dog. Am.J. Physiol. 238 (Heart Circ. Physiol. 7): H858-H867, 1980.

4. Boineau, J. P., and J. L. Cox. Slow ventricular activation in acute myocardial infarction. A source of re-entrant premature ventricular contractions. Circulation 43: 702-713, 1973.

5. De Jong, P. G. M., T. Arts, A. P. G. Hoeks, and R. S. Reneman. Determination of tissue motion velocity by correla- tion interpolation of pulsed ultrasonic echo signals. Ultrasonic Imaging 12: 84-98, 1990.

6. Delhaas, T., T. Arts, F. W. Prinzen, and R. S. Reneman. Relation between regional electrical activation time and subepicardial fiber strain in the canine left ventricle. Pfluegers Arch. 423: 78-87, 1993.

7. Delhaas, T., T. Arts, F. W. Prinzen, and R. S. Reneman. Regional fibre stress-fibre strain area as estimate of regional blood flow and oxygen demand in the canine heart. J. Physiol. Lond. 477: 481-496, 1994.

8. Elharrar, V., P. R. Fostex, T. L. Jirak, W. E. Gaum, and D. P. Zipes. Alterations in canine myocardial excitability during ischemia. Circ. Res. 40: 98-105, 1977.

9. Gallagher, K. P., G. Osakada, O. M. Hess, J. A. Koziol, W. S. Kempper, and J. Ross, Jr. Subepicardial segmental function during coronary stenosis and the role of myocardial fiber orientation. Circ. Res. 50: 352-359, 1982.

10. Glower, D. D., J. A. Spratt, J. S. Kabas, J. W. Davis, and J. S. Rankin. Quantification of regional myocardial dysfunction after acute ischemic injury. Am. J. Physiol. 255 (Heart Circ. Physiol. 24): H85-H93, 1988.

11. Guth, B. D., R. Schulz, and G. Heusch. Evaluation of parameters for the assessment of regional myocardial contractile function during asynchronous left ventricular contraction. Basic Res. Cardiol. 85: 550-562, 1990.

12. Heusch, G. The relationship between regional blood flow and contractile function in normal, ischemic, and reperfused myocardium. Basic Res. Cardiol. 86: 197-218, 1991.

13. Hotta, S. The sequence of mechanical activation of the ventricle. Jpn. Circ. J. 31: 1568-1572, 1967.

14. Janse, M. J., and A. L. Wit. Electrophysiological mechanisms of ventricular arrhythmias resulting from myocardial ischemia and infarction. Physiol. Reu. 69: 1049-1169, 1989.

15. Kléber, A. G., M. J. Janse, F. J. L. Van Capelle, and D. Durxer. Mechanisms and time course of ST and TQ segment changes during acute regional ischemia in the pig heart determined by extracellular and intracellular recordings. Circ. Res. 42: 603-613, 1978.

16. Muijtjens, A. M. M., J. M. A. Roos, T. T. Prinzen, A. Hasman, R. S. Reneman, and T. Arts. Noise reduction in estimating epicardial deformation from marker tracks. Am. J. Physiol. 258 (Heart Circ. Physiol. 27): H599-H605, 1990.

17. Opie, L. H., M. Thomas, P. Owen, and G. Shulman. Increased coronary venous inorganic phosphate concentrations during experimental myocardial ischemia. Am. J. Cardiol. 30: 503-513, 1972.

18. Pogwidz, S. M., and P. B. Corr. Electrophysiologic mechanisms underlying arrhythmias due to reperfusion of ischemic myocardium. Circulation 76: 404-426, 1987.

19. Prinzen, F. W., R. Alewijnse, G. J. van der Vusse, R. T. I Kruger, T. van der Nagel, and $\mathbf{R}$. S. Reneman. Coronary artery stenosis controlled by distal perfusion pressure: description of the servo-system and time-dependent changes in regional myocardial blood flow. Basic Res. Cardiol. 82: 375-387, 1987.

20. Prinzen, F. W., T. Arts, G. J. van der Vusse, W. A. Coumans, and R. S. Reneman. Gradients in fiber shortening and metabolism across ischemic left ventricular wall. Am. J. Physiol. 250 (Heart Circ. Physiol. 19): H255-H264, 1986.

21. Prinzen, F. W., C. H. Augustijn, M. A. Allessie, T. Arts, T. Delhaas, and R. S. Reneman. The time sequence of electrical and mechanical activation during spontaneous beating and ectopic stimulation. Eur. Heart J. 13: 535-543, 1992.

22. Prinzen, F. W., C. H. Augustijn, T. Arts, M. A. Allessie, and R. S. Reneman. Redistribution of myocardial fiber strain and blood flow by asynchronous electrical activation. Am. J. Physiol. 259 (Heart Circ. Physiol. 28): H300-H308, 1990.

23. Prinzen, F. W., G. J. van der Vusse, T. Arts, T. H. M. Roemen, W.A. Coumans, and R. S. Reneman. Accumulation of nonesterified fatty acids in ischemic canine myocardium. Am. J. Physiol. 247 (Heart Circ. Physiol. 16): H264-H272, 1984.

24. Prinzen, T. T., T. Arts, F. W. Prinzen, and R. S. Reneman. Mapping of epicardial deformation using a video processing technique. J. Biomech. 19: 263-273, 1986. 
25. Ramanathan, K. B., M. M. Bodenheimer, V. S. Banka, and R. H. Helfant. Electrophysiologic effects of partial coronary occlusion and reperfusion. Am. J. Cardiol. 40: 50-54, 1977.

26. Ruffy, R., D. E. Lovelace, T. M. Mueller, S. B. Knoebel, and D. P. Zipes. Relationship between changes in left ventricular bipolar electrograms and regional myocardial blood flow during acute coronary artery occlusion in dogs. Circ. Res. 45: 764-770, 1979.

27. Russell, D. C., R. A. Riemersma, J. S. Lawrie, and M. F. Oliver. Patterns of flow and conduction during early ventricular arrhythmias following coronary arterial occlusion in the dog. Cardiovasc. Res. 16: 613-623, 1982.

28. Scher, A. M., and M. S. Spach. Cardiac depolarization and repolarization and the electrocardiogram. In: Handbook of Physiology. The Cardiovascular System. The Heart. Bethesda, MD: Am. Physiol. Soc., 1979, sect. 2, vol. I, chapt. 9, p. 357-392.

29. Tennant, R., and C. J. Wiggers. The effect of coronary occlusion on myocardial contraction. Am. J. Physiol. 112: 351-361, 1935 .
30. Van der Vusse, G. J., T. H. M. Roemen, F. W. Prinzen, W. A. Coumans, and R. S. Reneman. Uptake and tissue content of fatty acids in dog myocardium under normoxic and ischemic conditions. Circ. Res. 50: 538-546, 1982.

31. Weintraub, W. S., S. Hattori, J.B.Agarwal, M. M. Bodenheimer, V. S. Banka, and R. H. Helfant. The relationship between myocardial blood flow and contraction by myocardial layer in the canine left ventricle during ischemia. Circ. Res. 48: 430-438, 1981.

32. Wiegner, A., G. J. Allen, and O. H. L. Bing. Weak and strong myocardium in series: implications for segmental dysfunction. Am. J. Physiol. 235 (Heart Circ. Physiol. 4): H776-H783, 1978.

33. Wilensky, R. L., J. Tranum-Jensen, R. Coronel, A. A. M. Wilde, J. W. T. Fiolet, and M. J. Janse. The subendocardial border zone during acute ischemia of the rabbit heart: an electrophysiologic, metabolic, and morphologic correlative study. Circulation 74: 1137-1146, 1986.

34. Williamson, J. R. Glycolytic control mechanisms. II. Kinetics of intermediate changes during the aerobic-anoxic transition in perfused rat heart. J. Biol. Chem. 241: 5026-5036, 1966.

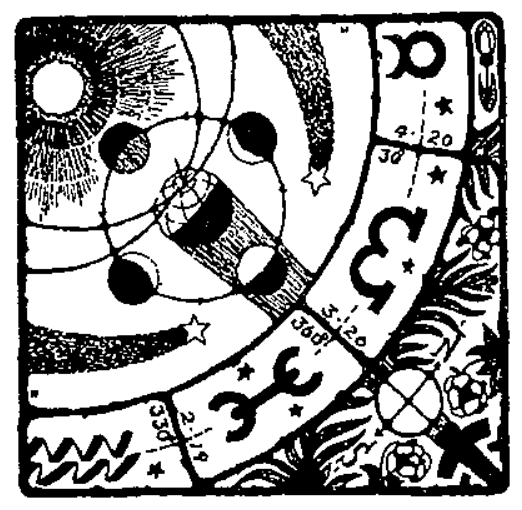

